\title{
A Comparative Phylogenic Analysis of Exacum spp. of Sri Lanka with Osbeckia octandra (L.) DC.
}

\author{
S. Maheswaran, V.A. Sumanasinghe ${ }^{1 *}$ and P. Samaraweera ${ }^{2}$ \\ Postgraduate Institute of Science \\ University of Peradeniya \\ Sri Lanka
}

\begin{abstract}
ABSTRAC: $\quad$ There are eight Exacum spp. (Family Gentianaceae) found in the wild in Sri Lanka namely, Exacum axillare, E. macranthum, E. pallidum, E. trinervium, E. walkerii, E. pedunculatum, E. petiolare and $\underline{E}$. sessile, of which four are designated as threatened species. This study was conducted to determine the phylogenetic relationships of four of the endemic Sri Lankan Exacum spp_which have shown a potential in the floriculture industry, namely $\underline{E}$. trinervium, E. macranthum, E. walkerii and $\underline{E}$. pedunculatum. with $\underline{E}$. affine (a non-endemic, commercial species) and to compare their sequences of the Internal Transcribed Spacer (ITS) region of 18S-26S rDNA for use as a possible DNA typing target. The study also compared the Exacum spp. of Sri Lanka with the morphologically similar species Osbeckia octandra. The DNA was isolated from tender leaves, the ITS region was amplified by Polymerase Chain Reaction (PCR) and the nucleotide sequences of the PCR products were determined. The amplified products of the ITS region of different species were estimated to be 554-720 bp. Multiple sequence alignment of the ITS sequences were carried out using ClustalW program and phylogenetic relationship of the species was determined by using Mega 4.0.2 package. The two endemic species $\underline{E}$. macranthum and E. trinervium, were the closest relatives and clustered together in the phylogenetic tree with E. walkerii. Exacum pedunculatum formed a separate cluster with the exotic species $\underline{E}$. affine, diverging from the cluster and branching separately. Osbeckia octandra diverged from all Exacum spp.
\end{abstract}

Keywords: Clustal W, Exacum spp., internal transcribed spacers, PCR, phylogenetics

\section{INTRODUCTION}

The Exacums are members of the Gentianaceae (tribe Exaceae) family. The Gentianaceae is a widespread cosmopolitan family of medium size, with 87 genera and about 1650 species (Struwe \& Albert, 2002). Species are spread around the Indian Ocean Bank, Africa, Madagascar, Socotra, the Arabian Peninsula, Sri Lanka, India, the Himalayas, and mainland Southeast Asia including southern China, Malaysia, and northern Australia. The majority of species (38 species) occurs in Madagascar (Yuan et al., 2005). Sri Lanka and the southern tip of the Indian subcontinent are the second most species-rich areas (Thulin, 2001).

Eight Exacum species are found in Sri Lanka, i.e. E. axillare Thw, E. macranthum Arn. ex. Griseb., E. pallidum (Trimen) Klack., E. trinervium (Trimen) Cramer, E. walkeri Arn., E. pedunculatum L., E. petiolare Griseb. and E. sessile L. (Klackenberg, 1983 and 1985). E.

Department of Agricultural Biology, Faculty of Agriculture, University of Peradeniya, Sri Lanka

2 Department of Molecular Biology and Biotechnology, Faculty of Science, University of Peradeniya, Sri Lanka.

* Corresponding author: sajanas@pdn.ac.lk 
affine Balf.f. ex Regel which is also found in Sri Lanka, is a non-endemic species. The species $O$. octandra (L.) DC. is superficially similar to Exacum sp. morphologically and has a medicinal value.

Ornamental value of Exacum was reported as early as in 1990's. Although beautiful, they are hard to cultivate (Woodrow, 1910). Of the recognized species, only E. affine L., native to Socotra, has been successfully domesticated and introduced to commercial floriculture. In the 1980's a great deal of effort was directed toward the development of improved E. affine cultivars. In recent years, the floriculture industry has again witnessed renewed interest in $E$. affine, with over 24 million units produced worldwide. Denmark leads total production with approximately $65 \%$, with the Netherlands adding an additional $20 \%$. However, both North American and Japanese growers are gaining a considerable percentage of overall production (Anderson, 2007).

The classification of the Exacums was done by various methods (Klackenberg, 1985). Morphological classifications, molecular classifications and other classifications based on biochemical constitutions and cytology have also been used for the past 25 years. But comparatively, molecular based comparisons, which include RAPD and SSR techniques and sequencing, provide reliable results. Molecular characterization of Sri Lankan Exacums was done using RAPD technique and the difference between the species was found (Sumanasinghe, et al., 2012). By sequencing both nuclear ribosomal internal transcribed spacers (ITS1 and ITS2) and the chloroplast trnL (UAA) intron, Yuan et al. (2003) conducted comprehensive molecular phylogenetic studies on this tribe by sampling all genera and additional species.

In this study, the molecular method using PCR technique and sequencing were used to find the phylogenetic relationship between the species. Within angiosperms the chloroplast rubisco large subunit ( $\mathrm{rbcL}$ ) gene has been widely sequenced and used for inferring plant phylogenies at higher taxonomic levels. The internal transcribed spacer (ITS) region of 18S26S nuclear ribosomal DNA (nrDNA) has also been proven to be a useful source of characters for phylogenetic studies in many angiosperm families. Phylogenetic methods are based on models of DNA sequence evolution and used to determine relationships among different organisms. Because the NCBI database contains sample sequences of representative plant species, phylogenetic methods are useful to determine or confirm the genus or family to which a sequence belongs.

This study was conducted to determine the genomic relationships of four of the Sri Lankan Exacum species, E. trinervium, E. macranthum, E. walkerii and E. pedunculatum with the non-endemic species, E. affine and morphologically analogous, endemic species Osbeckia octandra, which has a medicinal value by comparing the nucleotide sequence of ITS regions.

\section{MATERIALS AND METHODS}

\section{Sample collection}

E. affine was collected from the Plant House, National Botanic Gardens, Peradeniya. Plant materials of the other Exacums were collected from various localities in Sri Lanka. Collected leaves were stored at $-80^{\circ} \mathrm{C}$ for DNA extractions. All the species were checked and confirmed with the syntype specimens preserved at the National Herbarium, Peradeniya. 


\section{DNA extraction}

The extraction method was modified from Keb-Llanes et al. (2002). The moisture from the leaves was removed using clean tissue papers. The leaf sample was ground with $3 \mathrm{ml}$ of Extraction Buffer-A, $8 \mathrm{ml}$ of Extraction Buffer-B and $200 \mu \mathrm{l}$ of $\beta$-mercaptaethanol until it formed a fine paste. The content was transferred to a centrifuge tube and $500 \mu 1$ of $10 \%$ SDS solution and $5 \mu \mathrm{l}$ of $20 \mu \mathrm{g} / \mu \mathrm{l}$ protinase $\mathrm{K}$ were added. This was mixed well by vortexing and incubated in a water bath at $65^{\circ} \mathrm{C}$ for 1 hour. $5 \mathrm{M}$ potassium acetate $4.1 \mathrm{ml}$ was added to the paste, mixed by inverting and the tubes were kept in ice for 8-10 minutes. The contents were centrifuged at $6400 \mathrm{~g}$ for 25 minutes at $4^{\circ} \mathrm{C}$. The clear supernatant was transferred to another tube and equal volume of chloroform: isoamyl alcohol (24:1) was added and mixed for 15 minutes by inverting the tube. The tubes were centrifuged for $6400 \mathrm{~g}$ for 25 minutes at $4{ }^{\circ} \mathrm{C}$. The aqueous phase was transferred to a new tube and equal volume of ice cold isopropanol was added, mixed gently and kept in deep freezer for 20 minutes. The tube, after thawing, was centrifuged at $6400 \mathrm{~g}$ for 25 minutes at $4{ }^{\circ} \mathrm{C}$. The pellet formed in the centrifuge tube was washed with $70 \%$ ethanol, air dried and dissolved in TE buffer (pH.8.1). Five milliliters of RNAse $(10 \mathrm{mg} / \mathrm{ml})$ was added to the DNA dissolved in TE buffer and the solution was kept for incubation at $37{ }^{\circ} \mathrm{C}$ for 1 hour. An equal volume of phenol: chloroform: isoamyl alcohol (25:24:1) was added to it and mixed by inverting gently and centrifuged at $8800 \mathrm{~g}$ for 5 minutes. To the transferred aqueous layer an equal volume of chloroform: isoamyl alcohol (24:1) was added and centrifuged at $8800 \mathrm{~g}$ for 5 minutes. A $1 / 10$ volumes of $3 \mathrm{M}$ sodium acetate ( $\mathrm{pH} 5.2)$ and two volumes of $100 \%$ absolute ethanol was added to the transferred aqueous layer. The sample was stored overnight at $4{ }^{\circ} \mathrm{C}$ and centrifuged at $8800 \mathrm{~g}$ for 20 minutes. The resulted pellet was washed with $70 \%$ alcohol, dried and re-suspended in TE buffer. The genomic DNA was stored in $-80{ }^{\circ} \mathrm{C}$ for further experiments. The genomic DNA was confirmed by performing gel electrophoresis on $1.5 \%$ agarose gel.

\section{PCR amplification}

Primers ITS4 (TCCTCCGCTTATTGATATGC) and ITS5

(GGAAGTAAAAGTCGTAACAA GG), were used for the amplification of the ITS region of the nuclear ribosomal DNA for the samples. PCRs were performed in a $20 \mu 1$ mixture containing $0.2 \mathrm{mM}$ (each) deoxynucleoside triphosphates, $0.4 \mu \mathrm{M}$ concentrations of each primer, $0.4 \mathrm{U}$ of Taq DNA polymerase, $1 \mathrm{X}$ PCR buffer, and $5 \mu \mathrm{l}$ of DNA template. The reaction was carried out in a thermal cycler under the following conditions: Initial denaturation at $95^{\circ} \mathrm{C}$ for $5 \mathrm{~min}$, followed by 35 cycles of amplification at $95^{\circ} \mathrm{C}$ for $1 \mathrm{~min}$, $50^{\circ} \mathrm{C}$ for $1 \mathrm{~min}$, and $72^{\circ} \mathrm{C}$ for $2 \mathrm{~min}$, with a final extension at $72^{\circ} \mathrm{C}$ for $5 \mathrm{~min}$. The presence of PCR products was confirmed by agarose gel electrophoresis. The sequencing was done at Genetech Research Institute, Colombo.

\section{DNA sequence data analysis}

The ITS sequences of the Exacum sp. and $O$. octandra were compared with the available sequences in the NCBI database using the BLAST program. These sequences were aligned using a Clustal $\mathrm{W}$ multiple sequence alignment tools in the MEGA 4.0.2 (Kumar et al., 2008) and the phylogenetic tree was constructed by using the same software program. 


\section{RESULTS AND DISCUSSION}

The results of $1.5 \%$ agarose gel electrophoresis of PCR products are shown in Fig. 1. The desired PCR products were obtained between 700-600bp. The expected size of the amplified ITS region is $625 \mathrm{bp}$. The PCR products of all the Exacums and O. octandra gave nearly the same band size. But when sequenced, the sequence of $O$. octandra deviated significantly from other five sequences.

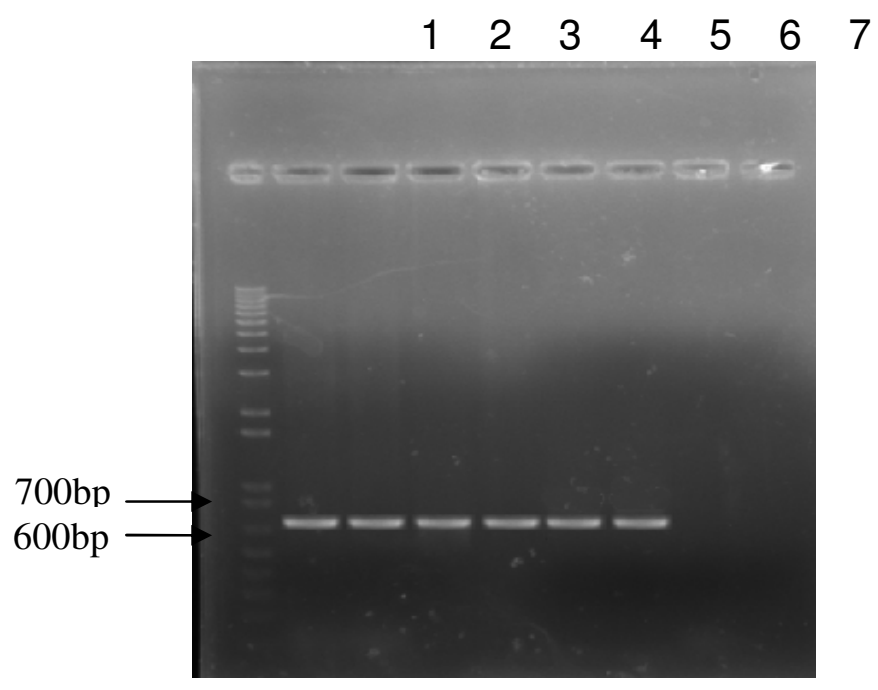

Fig. 1. Electrophoresis of amplified PCR products in $1.5 \%$ agarose gel. $1.1 \mathrm{~kb}$ Ladder; 2. E. trinervium; 3. E. macrantham; 4. E. pedunculatum; 5. E. walkerii; 6. E. affine; 7. Osbeckia octandra

Purified sequencing products were dissolved in $25 \mu \mathrm{l}$ of $\mathrm{Hi}-\mathrm{Di}^{\mathrm{TM}}$ Formamide (Applied Biosystem, USA (Part. No.4311320) and sequenced by programming the ABI Prism® 310 Genetic Analyzer (Applied Biosystem, USA). A representative sequencing reaction profile is shown in Fig. 2.

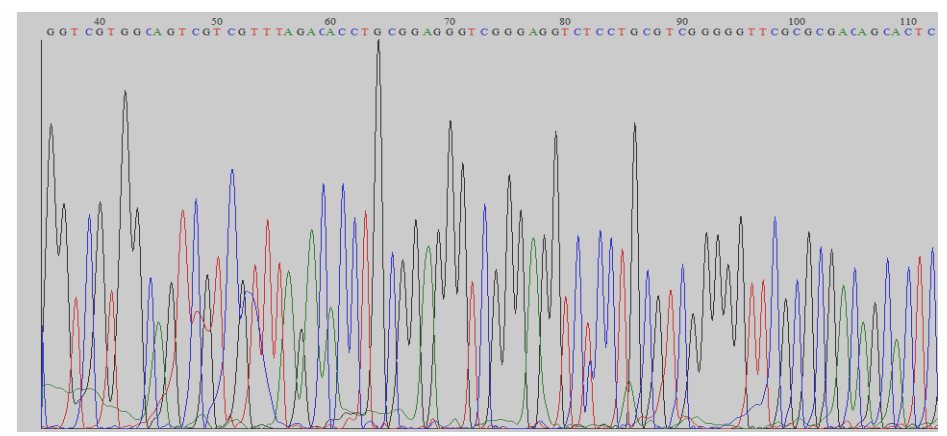

Fig. 2. ITS sequence of E. trinervium in Bio Edit program. 
The sequences were checked manually and meticulously to avoid any sequencing errors such as mismatches, indels or weak bands, and corrected. The ITS sequences of the Exacum $s p$. (Fig. 2) were compared with the available sequences in the National Center for Biotechnology Information (NCBI) database using the BLAST program to compare the sequence similarity, E- value, scores and query coverage. Except $E$. walkerii which showed $81 \%$ query coverage, all the other sequences had the $100 \%$ query coverage (Table 1). It was due to the dissimilarities of the bases of E. walkerii and also because the 5' end and 3' end of the sequence varied and did not match the existing sequence.

Table 1. Results obtained from NCBI- BLAST for entire ITS sequences.

\begin{tabular}{lccccc}
\hline Species & $\begin{array}{c}\text { Length of the } \\
\text { original } \\
\text { sequence }\end{array}$ & $\begin{array}{c}\text { Max score } \\
\text { /Total score }\end{array}$ & $\begin{array}{c}\text { Query } \\
\text { coverage }\end{array}$ & $\begin{array}{c}\text { E } \\
\text { value }\end{array}$ & $\begin{array}{c}\text { Max } \\
\text { identity }\end{array}$ \\
\hline E. trinervium & 554 & 881 & $100 \%$ & 0.0 & $96 \%$ \\
\hline E. macranthum & 555 & 933 & $100 \%$ & 0.0 & $97 \%$ \\
\hline E. walkerii & 655 & 630 & $87 \%$ & 0.0 & $88 \%$ \\
\hline E. pedunculatum & 719 & 1014 & $100 \%$ & 0.0 & $99 \%$ \\
\hline E. affine & 556 & 977 & $100 \%$ & 0.0 & $98 \%$ \\
\hline O. octandra & 720 & 797 & $100 \%$ & 0.0 & $94 \%$ \\
\hline
\end{tabular}

To obtain a reliable phylogenic tree, the regions which were in the very inception and the termination of the whole sequences were ignored and the 'proper region' was deployed in the Clustal W program.

A representative graphical output of multiple sequence alignment is shown in Fig. 3. E. macranthum and $E$. trinervium sequences were aligned with each other better than with the other three sequences E. pedunculatum, E. walkerii and E. affine (Fig. 4) As expected, sequence of $O$. octandra deviated from all other sequences.

All the Exacum sequences aligned well, implying the similarities between the endemic species with the exotic species. One would expect these to be different as they are from two different continents. However, the higher degree of homology indicates the conserved nature of ITS region. Yet, there was a deletion observed in the ITS2 region of E. walkerii and it was not observed in the sequence which is available at NCBI database. The deletion might have occurred due to an error in the sequencing process. 

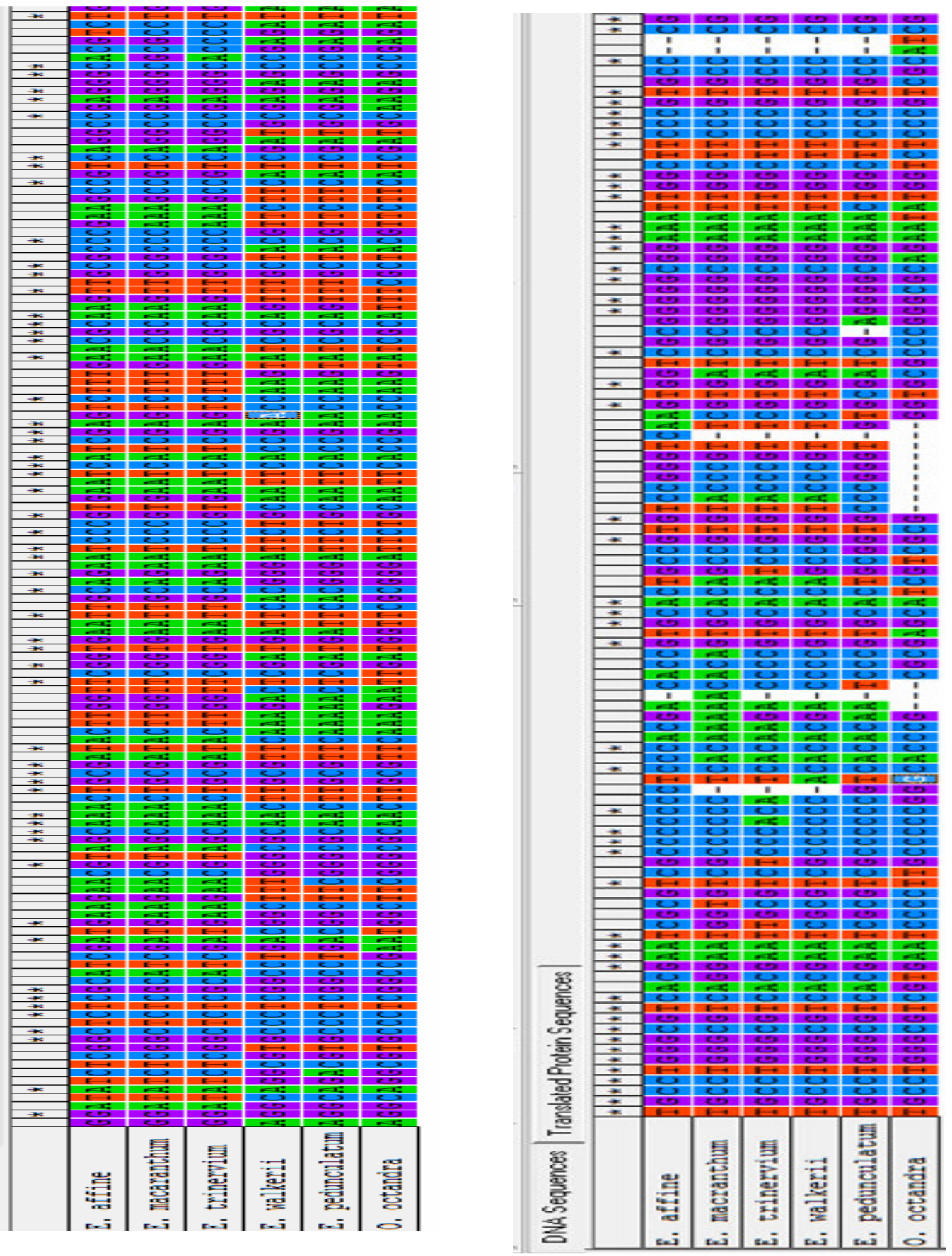

Fig. 3. Multiple alignment of all the sequences using the Mega 4 software. Given are fragments of the whole sequence as representatives. 
affine

TTAAACTCACGGGCGTCGGGACGGGGGAAACCACCGCCCGTC

GCC

pedunculatum

TTTAACTCACGGGCGTCGGGACGGGGGAAACCACGGACCGGT

GCC

macranthum

CCCACGGGCGTCGGACACGGGGGAACCACGGACCGGCGCC

trinervium

TAGAGACCACGGGCGTCGGAAAGGGGGATACCACGCCACGGC GCC

walkerii TTTGACGC-

CGGGGGTTGGGGAGGGGGA-ACCAGAGCCGCGCCAA

$\star \star * * * * * * * \quad * * * * \quad * * * *$

affine

CCGCGCACGGCGTCGGCCGCACGGCCGTTAGACGTGCAGAAA ACAAACCCGGGCGCGAAA

pedunculatum

CCGCGCGCGGCGTCGGCCGAAAGGCCGTTCTCCGTGCAAAAC

CAAAACCCGGGCGCGATA

macranthum

CCGCGCACGGCGTCGACCTCACGGTCGT-

CTCCTTGCGAAACACAAACTCGGGCGTGAAA

trinervium

CCGCGCACGGCGTCGACCTCACGGTCGT-

CTCCTTGCGAAACACAAACTCGGGCGTGAAA

walkerii CCGGGCAAGGC-TTGTCCTC-

CGGTTGG--TTCCTGGGAAACAAAAACTTGGGCGTGA-A $\star * \star \star * * * * \star \star * *$

affine

CGAGTCCCTCGCGGCGGACGCGACGACAAGTGGTGG TTGATTGCCTCAACTCGAGTGCTG

pedunculatum

CGAGTCCCTCGCGGCGGACGCGACGACAAGTGGTGG TTGATTGCCTCAACTCGAGTCCTG

macranthum

CGAGTCCCTTGCGGCGGGCGCGACGACAAGTGGTGG TTGATTACCTCAACTCGAGTGCTG trinervium

Fig. 4. Multiple alignment of entire ITS

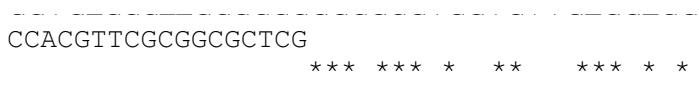

affine

CGGAGGAACACCCGCGTCTGTCGAAAATAAAACGACTCTCGG CAACGGATATCTCGGCT

pedunculatum

GGGGGGAGTACGGGCGTCTGTCAAAACTGAAACGACTCTCGG

CAACGGATATCTCGGCT

macranthum

CGGGAGGAGCACGGGCGTGTGTCGAAACTAAAACGACT

CTCGGCAACGGATATCTCGGCT

trinervium

CGGGAGGAGCACGGGCGTGTGTCAAAACTAAAACGACT CTCGGCAATGGATATCTCGGCT

walkerii

CGGAAGGAGCACGGGCGCGTGTCGAAACAAAAACGACT

CTCGCCAACGATTATCTCGGCT 
Since $5.8 \mathrm{~s}$ is expected to be a conserved gene, these sequences should be more similar amongst species. To demarcate the $5.8 \mathrm{~s}$ from the whole sequence, all the five sequences were aligned with the NCBI sequences individually and separately marked. Then the 5.8 s regions were aligned together in order to identify if there are differences among these five sequences. As shown in Fig. 5, 5.8s region in all species aligned well except 20 bases out of 160 bases in E. pedunculatum and E. affine.

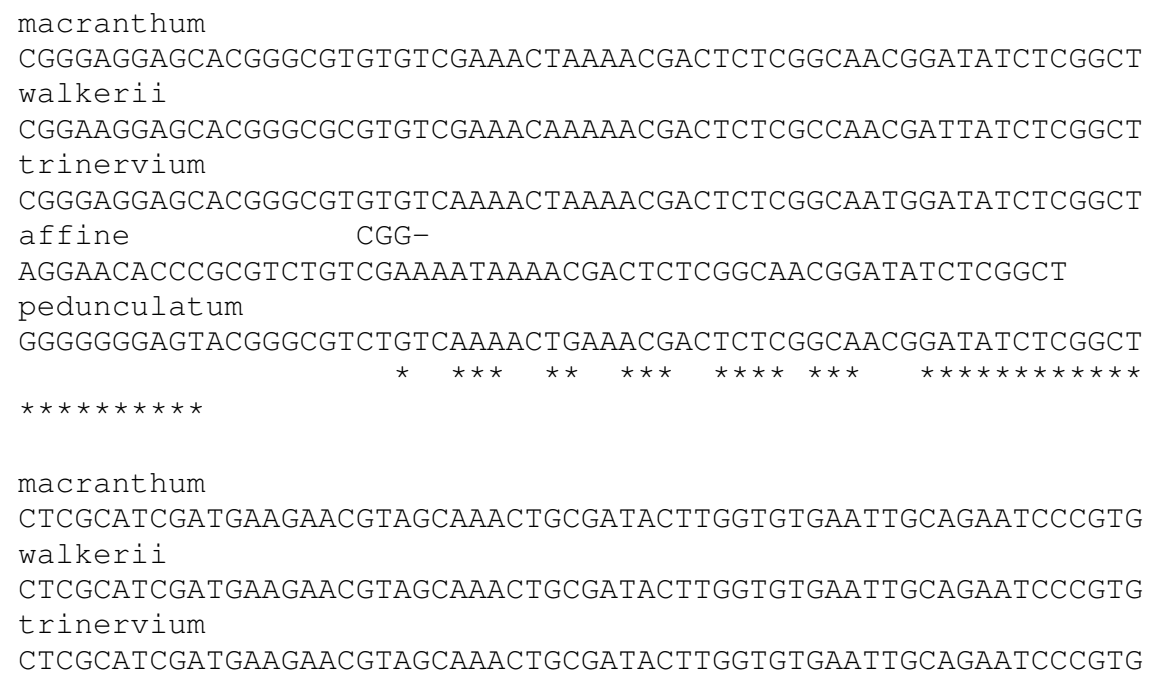

\section{Fig 5. Multiple alignment of the 5.8 conserved gene using Clustl W program}

Although the 5.8s gene is considered to be the conserved region there were differences found in E. pedunculatum and in E. affine. After finding the position of the 5.8s gene, ITS 1 was designated as the region located before 5.8s and ITS 2 as the region after the 5.8s gene.

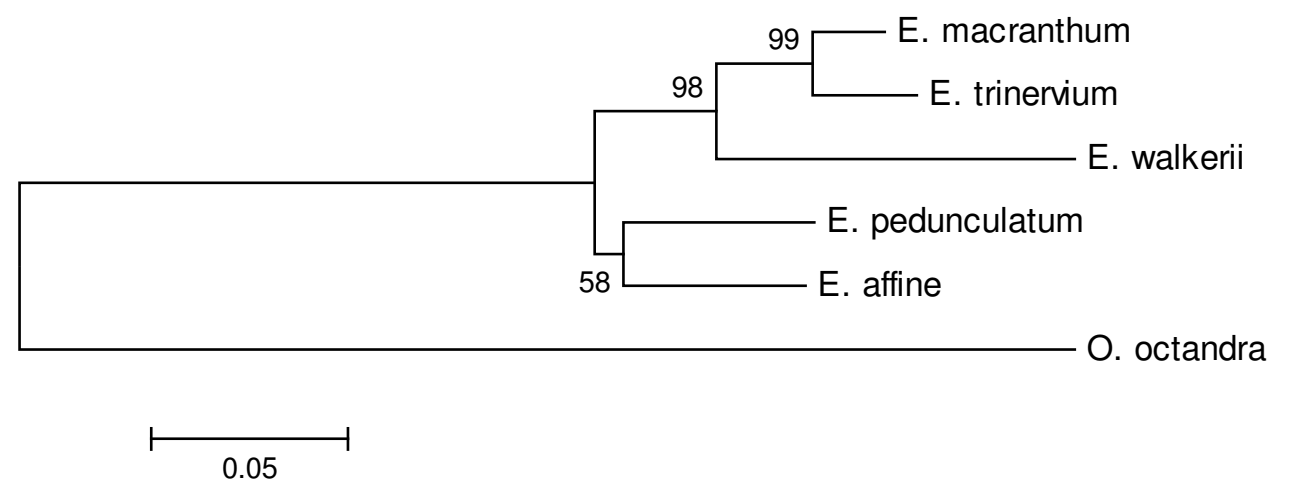

Fig. 6. Evolutionary relationships of 6 taxa: The evolutionary history was inferred using the Maximum Parsimony method. 
As the Fig. 6 illustrates $E$. trinervium grouped with $E$. macranthum pooling them as the most related amongst the studied 6 species. In ITS 1 region and ITS 2 region E. trinervium and $E$. macranthum aligned well along with $E$. walkerii. When compared with E. walkerii the other two sequences had more similarities within them. E. pedunculatum, the $4^{\text {th }}$ species from Sri Lanka showed much variation compared to the other three species. However, E. affine, the exotic species, had less differences compared to E. pedunculatum. Sumanasinghe (1986) explained that the compatibility of both E. trinervium and E. macranthum species may be attributed to their inheritance from a common ancestor. The close relationship between $E$. macranthum and E. trinervium was also shown by Yuan et al. (2005) based on combined ITS and $t r n \mathrm{~L}$ sequences. Moreover, Yuan states that E. trinervium, E. macranthum and E. walkerii grouped together, while E. pedunculatum and $E$. affine share a common branch in the phylogenic tree, which supports our experimental results.

Riseman et al., (2006) evaluated the chromosome numbers and the sexual reproduction in Exacum species. Chromosome numbers were determined to be as follows: E. trinervium, $2 \mathrm{n}=60$, E. macranthum, $2 \mathrm{n}=54, E$. pedunculatum, $2 \mathrm{n}=56, E$. affine, $2 \mathrm{n}=36$. Even though the chromosome number differs between E. macranthum and E. trinervium, these were the only two species that exhibited compatibility at fertilization amongst all Sri Lankan Exacum taxa in an earlier study. In terms of cytogenetic, compatibility and electrophoretic studies it was also found that $E$. affine was the most divergent species. Consequently, it is expected that the Sri Lankan species to be more similar to each other than to the exotic species E. affine.

O. octandra shows superficial morphological resemblance to Exacums. These resemblances are in leaf shape, veination and floral attributes such as color, shape and general appearance of flowers, nature of growth and, even with habitats they were naturally growing in. $O$. octandra also yielded a PCR product as same as the Exacums. However, it exhibited a much different sequence and, it failed to align well implying a higher level of dissimilarities. The molecular dissimilarities in the light of morphological resemblences between them may be a result of convergent evolution of these two taxa. Accordingly, O. octandra deviated from all the Exacum species, understandably separating it to a different branch in the clustergram. The separation of these can be expected as the Exacums are from the family Gentianaceae of the sub class Asteridae and $O$. octandra is from the family Melastomataceae of a genetically distant subfamily Rosidae.

\section{CONCLUSION}

Of the five Exacum species studied, based on the ITS sequences, the Sri Lankan species $E$. macranthum and E. trinervium exhibited the highest genetic relationship (99\%). E. walkerii showed only partial similarity with them $(98 \%)$, whereas $E$. pedunculatum was much divergent. E. pedunculatum even shared a different branch in the clustergram with the exotic species E. affine confirming its divergence from others (58\%). Although O. octandra shows strong degree of resemblance in flower characteristics to Exacums, the sequence analysis expressed it to be genetically vastly distanced. 


\section{REFERENCES}

Anderson, N.O. (2007). Flower Breeding and Genetics: Issues, Challenges and Opportunities for the $21^{\text {st }}$ century. Springer, pp. $601-616$.

Dassanayaka, M.D., Fosberg, F.R., (1981) A Revised Handbook to the Flora of Ceylon. 3, pp. 55 - 66.

Keb-Llanes, M., Gonzalez, G., Chi-Manzanero, B., Infante, D. (2002). A Rapid and simple method for small-scale DNA extraction in Agavaceae and other tropical plants. Plant Molecular Biology Reporter. 20, 299a - 299e.

Klackenberg, J. (1983). A Re evaluation of the genus Exacum (Gentianaceae) in Ceylon. Nord. JSTOR Plant Biology. 3, 355 - 370.

Klackenberg, J. (1985). The genus Exacum (Gentianaceae). Opera Botanica. pp.84, 1-144.

Kumar, S., Nei, M., Dudley, J., Tamura, K., (2008). MEGA: A biologist-centric software for evolutionary analysis of DNA and protein sequences. Oxford Journals. 9(4), 299 - 306.

Riseman, A., Sumanasinghe, V.A., Craig, R. (2006). Cytology, crossability and pollen fertility of Sri Lankan Exacum (Gentianaceae) and their hybrids. International Journal of Plant Sciences. 167(2), 191 - 199.

Struwe, L., Albert, V.A. (2002). Gentianaceae: Systematic and Natural History. The syndicate of the University of Cambridge, Cambridge, United Kingdom,pp.78 - 82.

Sumanasinghe, V.A. (1986). Electrophoretic, Cytogenetic, Crossability and Morphological Studies of Exacum (Gentianaceae). PhD Dissertation. Pennsylvania State University, USA.

Sumanasinghe, V.A., Karunasena. K.D.I.P., and Wijesundera, D.S.A. (2012). Molecular Characterization of Selected Sri Lankan Exacum Species. International Conference on Agriculture, Chemical and Environmental Sciences, Dubai, pp.78 - 80.

Thulin, M. (2001). Two new Species of frankincense trees (Beswellia, Burseraceae) from Socotra. Kew Bulletin . 56, 983 - 988.

Woodrow, G.M. (1910). Gardening In the Tropics. Paisley: Alexander Gardner, London, pp. $395-396$.

Yuan, Y.M., Wohlhauser, S., Moller, M., Chassot, P., Mansion, G., Gran, T. J., Kupfer, P. and Klackenberg, J. (2003). Monophyly and relationships of the tribe Exaceae (Gentianaceae) inferred from nuclear ribosomal and chloroplast DNA sequences. Molecular Phylogenetics and Evolution. 28, 500 - 517.

Yuan, Y.M., Wohlhauser, S., Moller, M., Klackenberg, J., Callmander, M.W. and Kupfer, P. (2005). Phylogeny and biogeography of Exacum (Gentianaceae): A disjunctive distribution in the Indian Ocean Basin resulted from long distance dispersal and extensive radiation. Systematic Biology. 54(1), 21 - 34. 